\title{
Features of the port retaining structure calculations
}

\author{
Vitalii Sidorov* and Yuliya Vanina \\ Moscow State University of Civil Engineering, Yaroslavskoe shosse, 26, Moscow, 129337, Russia
}

\begin{abstract}
Contrary to the considerable experience of designing, construction and operation of hydraulic construction of the bulwark type, there are still emergencies that exceed the normative values of deformations, displacements, rotation angles, loss of stability both during the staged construction and at the completion of construction. The question of taking into account the interaction of various complicating factors in the system "retaining structure-soft saturated soil base" is currently fundamental when choosing the type of element of structures, technology and the time of their construction. As a task, the interaction of a thinwalled bulwark on a soft saturated soilbase with the ice and seismic impacts was considered. Numerical research performed using PLAXIS 2D. Prediction of the interaction of the berth construction with the soil base, taking into account the variety of loads and impacts, made it possible to identify exceedances of normative values of forces, bending moments, displacements, which requires further consideration of the issues of ensuring the safety operation phase of the berthing construction. The errors of designers to unfinished consolidation of soils, the non-linear behavior under various impacts will lead to emergency situations, especially in hydraulic engineering. The results of the article show the need to take into account the rate of loading of the base for correct accounting of the bearing capacity of soft soils.
\end{abstract}

\section{Introduction}

Currently, significant works are underway to build new ports and modernize existing ports, to develop new sea and river transport lines. The failure of designers to unfinished consolidation of soils, the non-linear behavior under various impacts is one of the main causes of emergency situations, especially in hydraulic engineering. Fast loading of soft water-saturated clay soils with sand filling causes a significant decrease in the bearing capacity of the base, as well as exceeding the allowable values of forces and deformations, the difference between the actual work of structures from design solutions. The geotechnical problems of designing berthing constructions are much more complicated when taking into account seismic, ice and other dynamic impacts [1-5]. This article presents the results of numerical search the interaction of a berthing structure with a soft watersaturated soil base with various loads and impacts.

\footnotetext{
* Corresponding author: vitsid@mail.ru
} 
SP 23.13330.2011 regulates the design of the foundations of hydraulic structures and specifies the general provisions for carrying out calculations for the first group of limit states in order to prevent loss of strength and stability of structures, exceeding the displacements of structures that affect the strength or stability of the structure as a whole or its main elements, and the second group - to prevent the impossibility of normal operation. For soil bases of structures exposed to dynamic effects, it is necessary to take into account the non-linear behaviour of interaction with the structure, respectively, when using appropriate geomechanical models of soils [6-8].

This topic has been studied in a number of other works, including foreign ones, for example, $\mathrm{C}$. $\mathrm{Xu}$ have studied the characteristics of consolidation under time-dependent loadings are also analysed and the influences of depth-dependent parameters [9]. G. Carnero have researched influence on the effective stress parameters obtained due to volumetric disturbance during the saturation process [10]. V. Mahmoudabadi have proposed to evaluate the ultimate bearing capacity and elastic settlement of shallow foundation incorporating the site specific hydrological parameters such as historical rainfall and water table records [11].

This topic has several approaches to the study that have emerged in the present. Among them are the development of models for the interaction of soil and structures. Y. Liu has developed for determining lateral earth pressure (LEP) behind the retaining wall and uplift friction along the single pile shaft in expansive soil using unsaturated soil mechanics [12]. Q. Gang and Jürgen Grabe (2012) [13] have carried out numerical modelling using the Coupled Eulerian-Lagrangian method has been carried out to investigate the shielding effect of pile rows on the active earth pressure in sand [14].

\section{Methods}

In this paper, the authors used the two-dimensional finite element model of the interaction of the berthing structure of bulwark type with soft water-saturated soil base. (Fig 1). The design parameters are presented in table 1 .

Table 1. The design parameters of berthing structure.

\begin{tabular}{|c|c|}
\hline The type of element & Specifications \\
\hline The front wall & Single GU22n, $\mathrm{l}=20 \mathrm{~m}$ \\
\hline Row of shielding steel piles on the water side & Pipe $\mathrm{d}=1220 \mathrm{~mm}, \mathrm{t}=14 \mathrm{~mm}, \mathrm{l}=26.5 \mathrm{~m}$ \\
\hline Row of shielding steel piles from the land & Pipe $\mathrm{d}=1220 \mathrm{~mm}, \mathrm{t}=12 \mathrm{~mm}, \mathrm{l}=35 \mathrm{~m}$ \\
\hline The anchor wall & Single GU22n, $\mathrm{l}=6 \mathrm{~m}$ \\
\hline Anchor & M80 \\
\hline
\end{tabular}

Geotechnical numerical calculations of the staged construction of the berthing structure was carried out in the PLAXIS 2D. The situation is calculated taking into account the staged construction, as well as consolidation at the stages of fill for anchor (120 days) and subsequent filling of the territory ( 15 days). Three calculated cases were considered:

1. Construction phase and operational phase with storage of goods load as the staggered distributed load with the values of $\mathrm{q} 1=48 \mathrm{kN} / \mathrm{m} 2, \mathrm{q} 2=72 \mathrm{kN} / \mathrm{m} 2, \mathrm{q} 3=120 \mathrm{kN} / \mathrm{m} 2$;

2. Ice impact as the horizontal concentrated force $\mathrm{Fcw}=486 \mathrm{kN}$;

3. Seismic impact as the prescribed displacement at the lower boundary of the model with the assignment of dynamic coefficients of the $\mathrm{x}$-component using accelerograms. 
The soil base is presented in the form of bedding soft water-saturated clay soils with low strength and deformation characteristics. The heterogeneous soil foundation is described as follows: the embankment is represented by the Linear Elastic model, the clay soils is described by the Hardening Soil model. The Hardening soil model is the most versatile and is suitable for modelling many varieties of soil bases. It is especially effective in calculations of heavily buried structures with significant additional loads, since it allows one to successfully simulate nonlinear deformations and residual displacements during unloading/reloading [15-16].

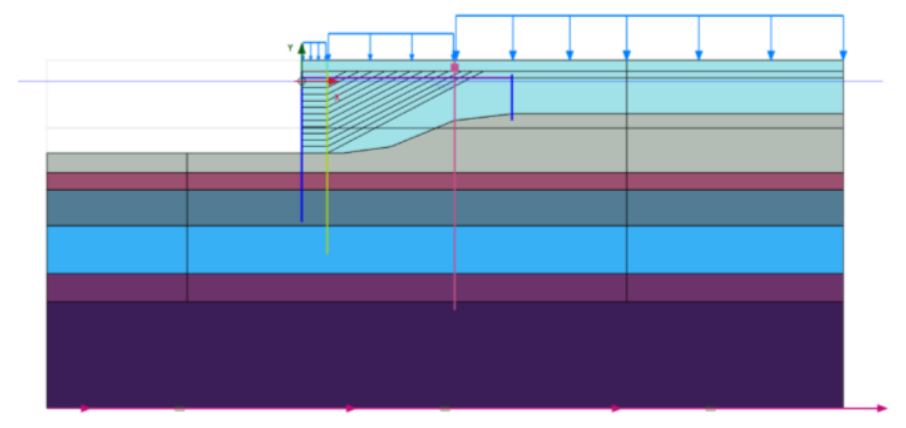

Fig. 1. Finite element model of shielded anchored retaining wall

\section{Results}

First design case (phased construction and operational phase). At the phase of the filling for the anchor wall excess pore pressure is $58.6 \mathrm{kPa}$. With a gradual increasing of the amount of filling material, there is a further increasing of the maximum values of excess pore pressure with further transformation of the isofields of excess pore pressure during the time. By the time the construction is completed, two areas are formed with maximum values of excess pore pressure $(145 \mathrm{kPa})$ in very soft-soft and very soft-firm loams under the ends of the front wall and shielding steel pile on the water side (Fig. 2,3). Also, the time for stabilization of a soft water-saturated base was calculates. For the criterion of stabilization was taken the point in time when the excess pore pressure will be $10 \%$ of its maximum value that occurs at this stage of loading [17-18]. The total time of dispersion of excess pore pressure at the phase of filling the anchor wall is 4337 days and at the phase of completion of the construction of the structure is 7742 days. This is due to the extremely low filtration characteristics of the soils. Consolidation of operational phase load was not taken into account. 


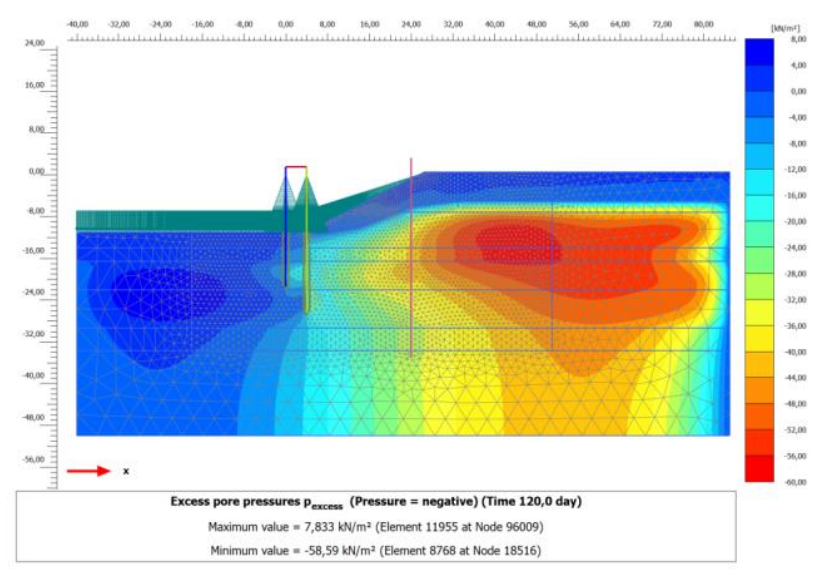

Fig. 2. Excess pore pressure at the phase of filling for the anchor wall

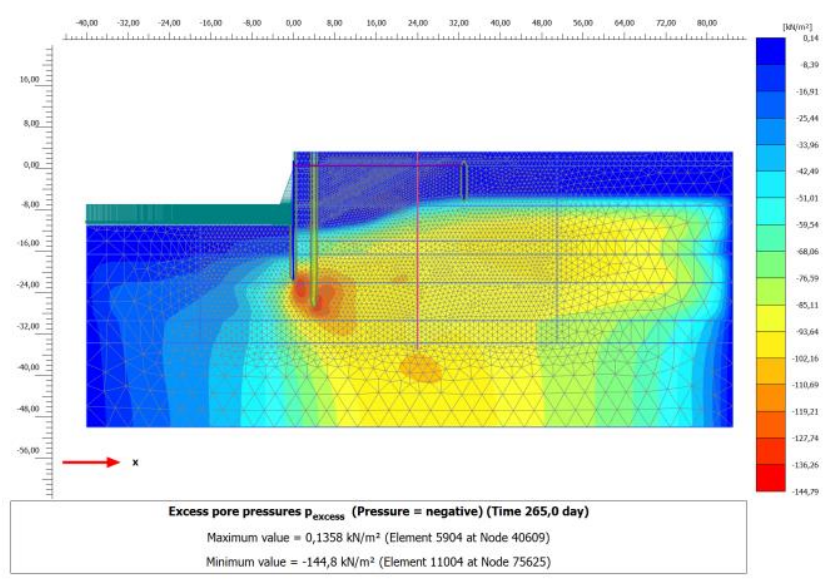

Fig. 3. Excess pore pressure at the phase of completion of the construction

Total horizontal displacements on the phase of completion of the berthing construction are directed towards the water side and exceed the maximum permissible values (Fig. 4). At the operation phase, the horizontal displacements of the structural elements exceed the values of the previous phase by 2.5 times (table 2). The values of the bending moments in the design do not exceed the normative.

Table 2. The results of calculations of operation phase

\begin{tabular}{|c|c|c|c|c|c|c|c|}
\hline \multirow{2}{*}{ № } & \multirow{2}{*}{ Units } & \multirow{2}{*}{$\begin{array}{c}\text { Front } \\
\text { wall }\end{array}$} & \multirow{2}{*}{$\begin{array}{c}\text { Row of } \\
\text { shielding } \\
\text { steel piles on } \\
\text { the water } \\
\text { side }\end{array}$} & \multirow{2}{*}{$\begin{array}{c}\text { Row of } \\
\text { shielding } \\
\text { steel piles } \\
\text { from the land }\end{array}$} & \multirow{2}{*}{$\begin{array}{c}\text { Anchor } \\
\text { wall }\end{array}$} & \multicolumn{2}{|c|}{ Anchor } \\
\hline & & & & & & Point 1 & Point 2 \\
\hline $\mathrm{U}_{\mathrm{x}(\max )}$ & $\mathrm{m}$ & 0.53 & 0.55 & 0.54 & 0.49 & 0.49 & 0.46 \\
\hline $\mathrm{U}_{\mathrm{y}(\max )}$ & $\mathrm{m}$ & 0.18 & 0.21 & 0.12 & 0.23 & 0.18 & 0.25 \\
\hline Max & $\begin{array}{c}\mathrm{kN} \cdot \mathrm{m} / \\
\mathrm{m}\end{array}$ & 354.8 & 2288.0 & 1227.0 & 84.0 & & \\
\hline
\end{tabular}




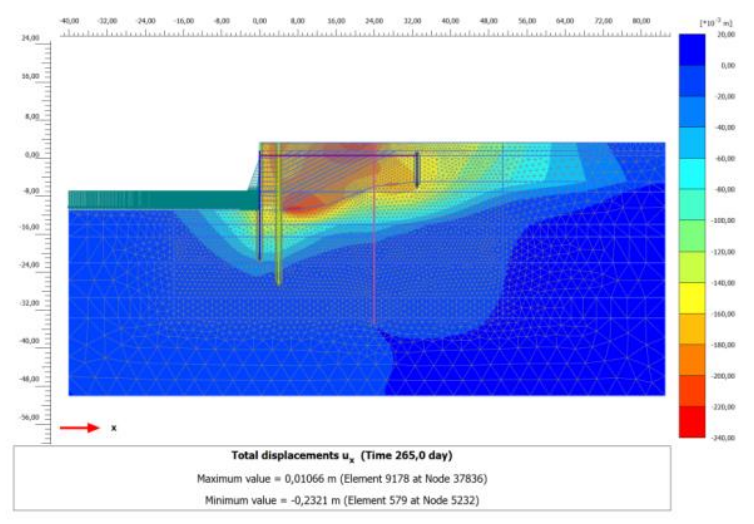

Fig. 4. Total horizontal displacements at the phase of completion of the construction. $\mathrm{U}_{\mathrm{x}, \max }=0.23 \mathrm{~m}$.

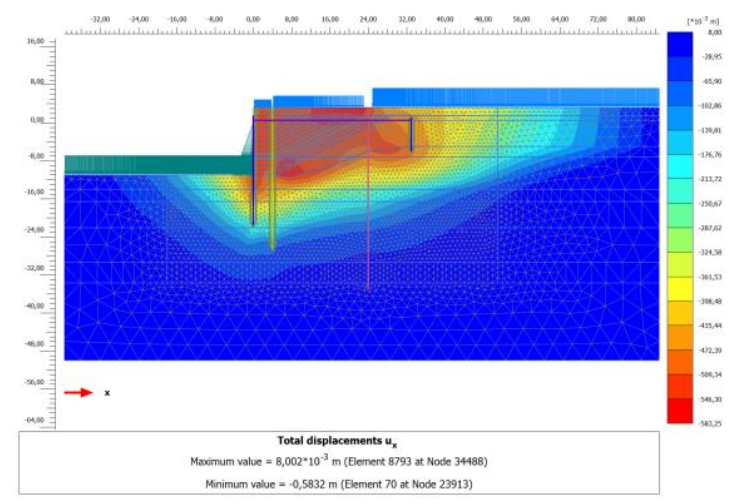

Fig. 5. Total horizontal displacements of operation phase. $U_{x, \max }=0.58 \mathrm{~m}$

Rapid loading of the soft water-saturated soils increases the excess pore pressure, which causes immediate shear deformations, and volume deformations occur in time. This may lead to a further increasing of horizontal displacement of the sand embankment towards the water side and increasing the displacement values of the structural elements of the berthing structure (Figure 5). Besides, there are differential settlements of structural elements.

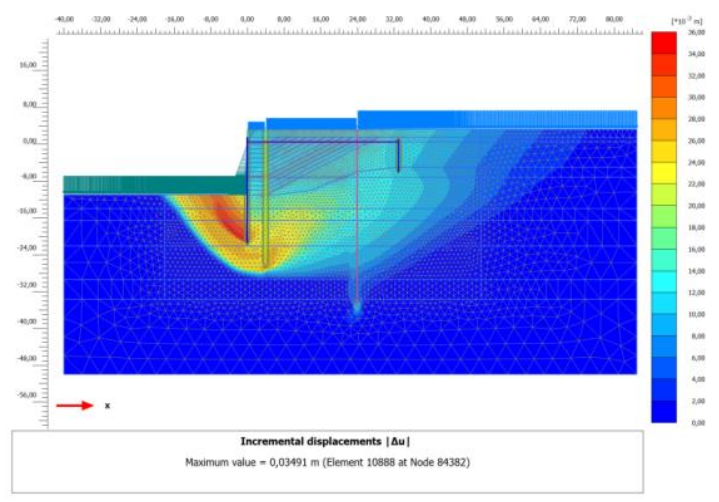

Fig. 6. Incremental displacements of operation phase. $\mathrm{K}_{\mathrm{st}}=1.91$ 
The impacts from of ice fields can reach high values. To determine the value of the ice impact, averaged ice parameters for the thickness $t=0.7 \mathrm{~m}$ were used. The calculation was carried out without taking into account the vertical component of the freezing force and the previously applied distributed load. The impact of the ice leads to a decreasing the safety coefficient (Fig. 8), and also causes a uniform horizontal displacement of the structure and sand fill towards the land by $1 \mathrm{~cm}$.

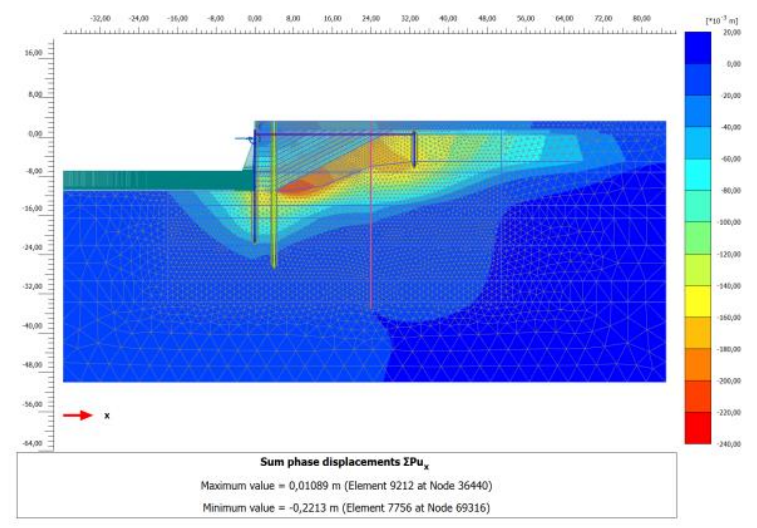

Fig. 7. Sum phase displacements under ice impact

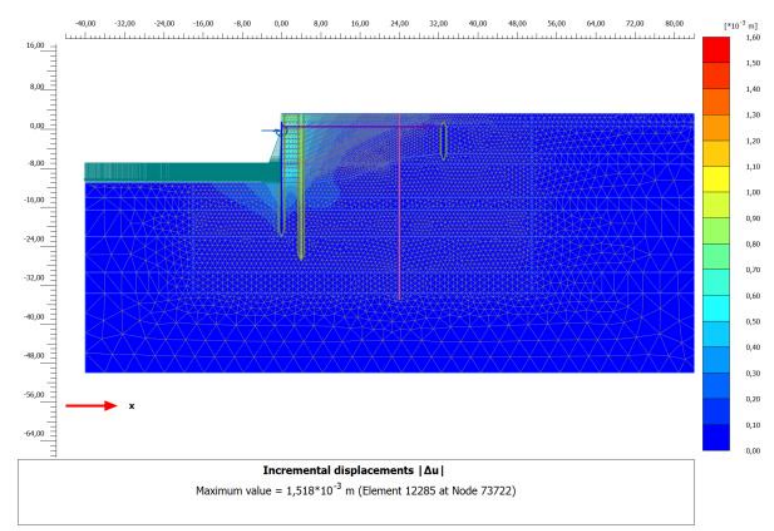

Fig. 8. Incremental displacements under ice impact. $\mathrm{K}_{\mathrm{st}}=1.19$

Ice impact causes the redistribution of the existing isofield of excess pore pressure (Fig. 9) with the formation of several regions with elevated values $(110 \mathrm{kPa})$. Thus, ice impacts increases the consolidation time of a soft water-saturated soilbase. 


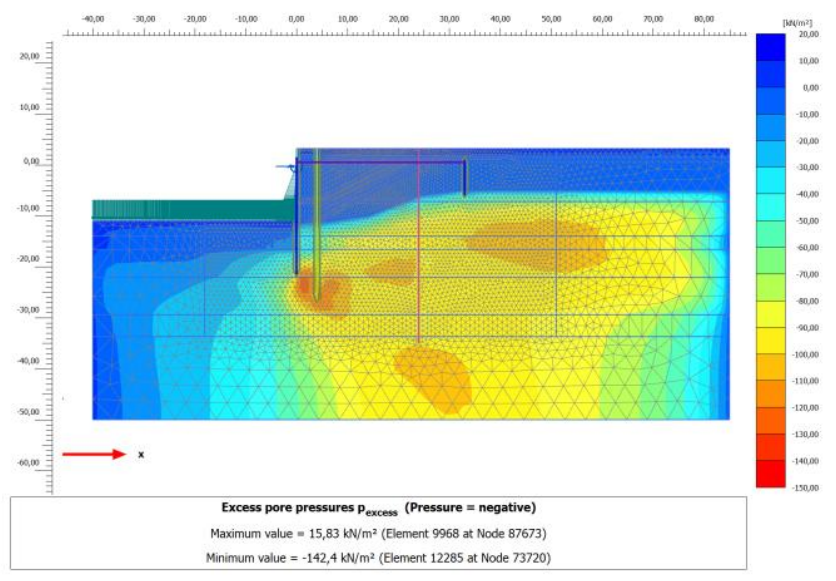

Fig. 9. Excess pore pressure under ice impact

Seismic impact (Fig. 10) causes an increase in the values of bending moments in each structure element by $15-50 \%$ compared with the phase of completion of construction. The calculation results are represented in table 3 .

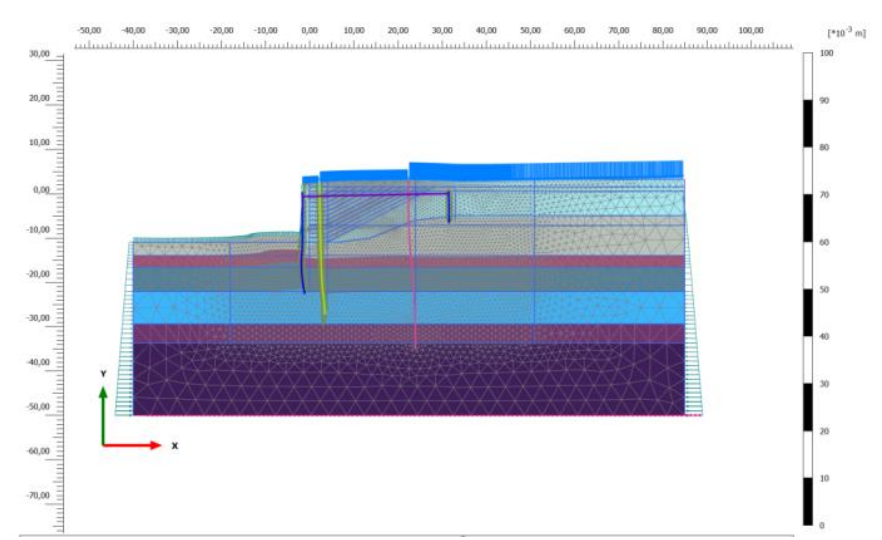

Fig. 10. Deformed mesh of phase of seismic impact

Table 3. The results of calculations of phase of seismic impact

\begin{tabular}{|c|c|c|c|c|c|c|c|}
\hline \multirow{2}{*}{ No. } & \multirow{2}{*}{ Units } & \multirow{2}{*}{$\begin{array}{c}\text { Front } \\
\text { wall }\end{array}$} & \multirow{2}{*}{$\begin{array}{c}\text { Row of } \\
\text { shielding } \\
\text { steel piles } \\
\text { on the } \\
\text { water side }\end{array}$} & \multirow{2}{*}{$\begin{array}{c}\text { Row of } \\
\text { shielding } \\
\text { steel piles } \\
\text { from the land }\end{array}$} & \multirow{2}{*}{$\begin{array}{c}\text { Anchor } \\
\text { wall }\end{array}$} & \multicolumn{2}{|c|}{ Anchor } \\
\hline & & & & & & Point 1 & Point 2 \\
\hline $\mathrm{U}_{\mathrm{x}(\max )}$ & $\mathrm{m}$ & $4.5 \cdot 10-3$ & $4.2 \cdot 10-3$ & $4.2 \cdot 10-3$ & $4.8 \cdot 10-3$ & $4 \cdot 10-3$ & $3 \cdot 10-3$ \\
\hline $\mathrm{U}_{\mathrm{y}(\max )}$ & $\mathrm{m}$ & $1.5 \cdot 10-5$ & $1.86 \cdot 10-5$ & $1.61 \cdot 10-5$ & $5 \cdot 10-4$ & $1.5 \cdot 10-3$ & $1.5 \cdot 10-3$ \\
\hline $\mathrm{M}_{\max }$ & $\begin{array}{c}\mathrm{kN} \cdot \mathrm{m} / \\
\mathrm{m}\end{array}$ & 148.9 & 2494.0 & 1887.0 & 125.6 & & \\
\hline
\end{tabular}

The graph of the dependence of the change in displacements on time is represented in Fig. 11, for several points located under each of the structural elements: A) under the front 
wall; B) under the first shield pile; B) under the second shield pile; D) under the anchor wall.

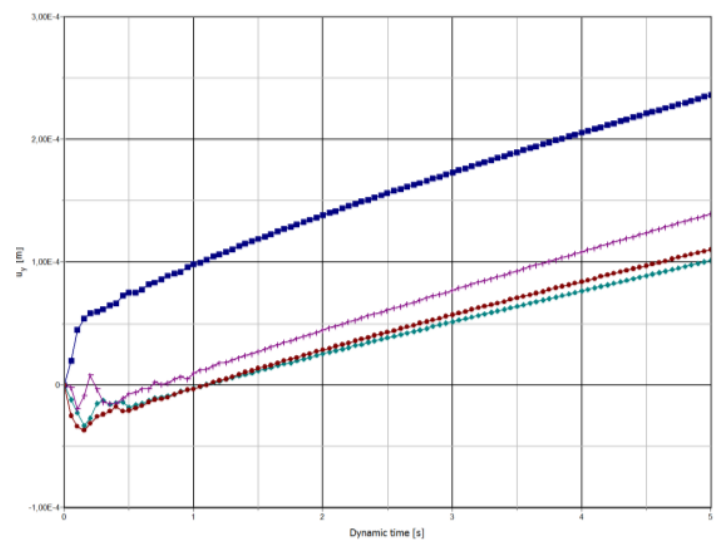

Point $A$

Point B

Point C

Point D

Fig. 11. The dependence of the change in displacements on time for the points located under each of the structural elements.

The seismic impact in the considered case does not cause significant general displacements of the construction. The biggest displacement was received by the front and anchor walls (points A and D).

\section{Discussions}

The main computational model of the soil foundation in hydraulic engineering is the Winkler foundation, implemented, for example, in SCAD, with a variable coefficient of subgrade resistance for the wall height and constant for the bottom for the front and anchor walls. However, it is known that in a water-saturated soil base of a finite width, a complex inhomogeneous stress-strain state is formed, which transforms in time when pore pressure dissipates to the draining boundaries of the computational domain. Thus, the Winkler foundation is not able to take into account the solutions of the theory of filtration consolidation, to fully predict the mechanism for the development of settlements and the dispersion of excess pore pressure. Correct prediction of the interaction of the berth construction with the soft saturated soil base, taking into account the variety of loads and impacts is possible using geomechanical models, for example Hardening Soil or Soft Soil Creep.

\section{Conclusions}

1. Horizontal displacement exceeds the normalized values in spite of ensured strength of the structural elements of the berth construction. The total time of dispersion of excess pore pressure at the phase of filling the anchor wall was 4337 days and at the phase of completion of the construction of the structure - 7742 days. System safety is ensured.

2. Ice impacts decreases the safety coefficient of the system "berth structure - soft watersaturated base".

3. During seismic impact, there is a significant increase in the values of bending moments of the structural elements. Reducing the negative impact of an earthquake is possible either by changing the dynamic characteristics of the structure, or by improving the mechanical properties of soil foundation. 


\section{References}

1. G. Qiu, J. Grabe, Acta Geotech, 7, 343-355 (2012)

2. C. Cherubini, Computers and Geotechnics 26, 309-330 (2000)

3. K. Upreti, E. Leong, Geotech. Sp. Publ., 303, 388-397 (2018)

4. A. Smolenkova, V. Korovkin, N. Orlova, K. Ragulin, A. Kuzina, Magazine of Civil Engineering, 72, 3-11 (2017)

5. H. Lei, S. Feng, Y. Jiang, Geom. and engin., 16, 125-140 (2018)

6. P. Kokkali, T. Abdoun, A. Tessari, Soil dyn. and earthq. engin., 113, 629-649 (2018)

7. M. Vinothkumar, K. Muthukkumaran, Sustainable Civil Infrastructures, (Springer International Publishing AG, Switzerland, 2018)

8. O. Ozutsumi, Geotech. Geol. and Earthq. Engin., 43, 341-365 (2018)

9. C. Xu, Q. Chen, L. Liang, X. Fan, Europ. J. of envir. and civ. eng., 22, 200-212 (2018)

10. G. Carnero, F. Marinho, Unsat. soils: research \& appl., 1, 203-209 (2014)

11. B. Ajmera, B. Tiwari, L. Nassruldin, Geotech. Sp. Publ., 295, 84-93 (2018)

12. Y. Liu, S. Vanapalli, Geotech. Sp. Publ., 303, 278-289 (2018)

13. A. Blomeke, R. House, S. Sadkowski, Geotech. Sp. Publ., 295, 418-430 (2018)

14. V. Mahmoudabadi, N. Ravichandran, Geotech. Sp. Publ., 303, 268-277 (2018)

15. T. Stark, P. Ricciardi, R. Sisk, Geotech. Pr. Publ., 11, 245-256 (2018)

16. M. Boone, M. Lewis, Geotech. Pr. Publ., 11, 257-271 (2018)

17. Y. Zhang, A. Zhou, Geotech. Sp. Publ, 301, 205-214 (2018)

18. P. Joseph, Dynamical systems-based soil mechanics, (CRC Press-Balkema, Netherlands, 2017) 